\title{
Do-it-Yourself Activism in Pakistan: The Fatal Celebrity of Qandeel Baloch - CORRIGENDUM
}

Zainab B. Alam

doi: $10.1017 / S 1537592719002408$. Published online by Cambridge University Press, 5 August 2019

In the original article by Alam (2019), on page 6 the term "Balochs" was erroneously published instead of "Baloch." Baloch is the plural form of this ethnic group. The corrected text is as follows: "Likewise, the Baloch are a politically and economically marginalized minority ethnic group in the region of Balochistan, a province that has made separatist claims since the country's foundation.
Typically labeled separatist troublemakers by the state, the Baloch are positioned as a threat to the integrity of the nation.”

\section{Reference}

Alam, Zainab B. "Do-it-Yourself Activism in Pakistan:

The Fatal Celebrity of Qandeel Baloch." Perspectives on

Politics. Published online 5 August 2019. doi: 10.1017/

S1537592719002408 